\title{
INTERPOLATION WITH A PARAMETER FUNCTION AND INTEGRABLE FUNCTION SPACES WITH RESPECT TO VECTOR MEASURES
}

\author{
Ricardo del CAmpo, Antonio Fernández, Antonio Manzano, \\ FERNANDO MAYORAL AND FRANCISCO NARANJO
}

Abstract. We establish interpolation formulae for different compatible couples formed by spaces of scalar integrable functions with respect to a vector measure in connection with a parameter function.

Mathematics subject classification (2010): Primary 46E30, Secundary 46G10, 46B42.

Keywords and phrases: Real interpolation; parameter function; vector measures; integrable function spaces; Lorentz-Zygmund spaces.

\section{REFERENCES}

[1] M. A. ARIÑo AND B. MucKenhoupt, Maximal functions on classical Lorentz spaces and Hardy's inequality with weights for nonincreasing functions, Trans. Amer. Math. Soc. 320, 2 (1990), 727-735.

[2] B. Beauzamy, Espaces d'interpolation réels: topologie et géométrie, Springer, Lecture Notes in Math. 666, Berlin, (1978).

[3] C. Bennett And R. Sharpley, Interpolation of operators, Academic Press Inc. Pure and Applied Mathematics 129, Boston, MA, (1988).

[4] J. BERGH AND J. LÖFSTRÖM, Interpolation spaces (An Introduction), Springer-Verlag, Grundlehren der Mathematischen Wissenschaften 223, Berlin, (1976).

[5] M. J. CARRo AND J. Soria, Boundedness of some integral operators, Canad. J. Math. 45, 6 (1993), $1155-1166$.

[6] J. Cerdà, J. Martín And P. Silvestre, Capacitary function spaces, Collect. Math. 62, 1 (2011), $95-118$.

[7] F. Cobos, L. M. Fernández-Cabrera, A. Manzano and A. Martínez, Real Interpolation and closed operator ideals, J. Math. Pures Appl. 83, 3 (2004), 417-432.

[8] F. Cobos, M. L. FernándeZ-Cabrera And H. Triebel, Abstract and concrete logarithmic interpolation spaces, J. London Math. Soc. 70, 1 (2004), 231-243.

[9] N. Dunford And J. T. Schwartz, Linear Operators. Part I, Wiley Classics Lib., John Wiley and Sons Inc., Grundlehren der Mathematischen Wissenschaften, New York, (1988).

[10] W. D. Evans AND B. OpIC, Real interpolation with logarithmic functors and reiteration, Canad. J. Math. 52, 5 (2000), 920-960.

[11] W. D. EvAns, B. OPIC AND L. PICK, Interpolation of operators on scales of generalized LorentzZygmund spaces, Math. Nachr. 182, (1996), 127-181.

[12] W. D. Evans, B. OPIC AND L. PICK, Real interpolation with logarithmic functors, J. Inequal. Appl. 7, 2 (2002), 187-269.

[13] A. Fernández, F. Mayoral AND F. NARAnjo, Real interpolation method on spaces of scalar integrable functions with respect to vector measures, J. Math. Anal. Appl. 376, 1 (2011), 203-211.

[14] A. Fernández, F. Mayoral, F. Naranjo, C. Sáez and E. A. Sánchez-Pérez, Spaces of $p$-integrable functions with respect to a vector measure, Positivity 10, 1 (2006), 1-16.

[15] A. GogatishVILI, B. OPIC AND W. TREBELS, Limiting reiteration for real interpolation with slowly varying functions, Math. Nachr. 278, 1-2 (2005), 86-107.

[16] J. GustavsSON, A function parameter in connection with interpolation of Banach spaces, Math. Scand. 42, 2 (1978), 289-305. 
[17] J. Gustavsson And J. Peetre, Interpolation of Orlicz spaces, Studia Math. 60, 1 (1977), 33-59.

[18] S. HeInRICH, Closed operator ideals and interpolation, J. Funct. Anal. 35, 3 (1980), 397-411.

[19] S. JANSON, Minimal and maximal methods of interpolation, J. Funct. Anal. 44, 1 (1981), 50-73.

[20] I. KluváneK And G. KNowles Vector measures and Control Systems, North-Holland, Notas Mat. 58, Amsterdam, (1975).

[21] S. G. Krein, Ju. I. Petunin And E. M. Semenov, Interpolation of linear operators, American Mathematical Society, Translations of Mathematical Monographs 54, Providence R.I., (1982).

[22] L. Maligranda, The $K$-functional for p-convexifications, Positivity 17, 3 (2013), 707-710.

[23] C. MERUCCI, Interpolation réele avec fonction paramètre: réitération et applications aux espaces $\Lambda^{p}(\varphi)(0<p \leqslant+\infty)$, C. R. Acad. Sc. Paris 295, 6 (1982), 427-430.

[24] P. Nilsson, Reiteration theorems for real interpolation and approximation spaces, Ann. Mat. Pura Appl. 32, 4 (1982), 291-330.

[25] S. OKADA, W. J. Ricker AND E. A. SÁncheZ-PÉREZ, Optimal Domain and Integral Extension of Operators Acting in Function Spaces, Birkhäuser-Verlag, Oper. Theory Adv. Appl. 180, Basel (2008).

[26] J. Peetre, A theory of interpolation of normed spaces, Instituto de Matemática Pura e Aplicada, Conselho Nacional de Pesquisas, Notas de Matemática, 39, Rio de Janeiro (1968). 
[27] L. E. Persson, Interpolation with a parameter function, Math Scand. 59, 2 (1986), 199-222.

[28] G. F. Stefansson, $L_{1}$ of a vector measure, Le Matematiche 48, 2 (1993), 219-234.

[29] V. D. StePAnOv, The weighted Hardy's inequality for nonincreasing functions, Trans. Amer. Math. Soc. 338, 1 (1993), 173-186. 